\title{
PANSHARPENING OF RASAT AND GÖKTÜRK-2 IMAGES VIA HIGH PASS FILTER
}

\author{
Oya Burcu Bakioğlu ${ }^{\mathrm{a}^{*}}$, Hüseyin Topan ${ }^{\mathrm{a}}$, Mustafa Özendi ${ }^{\mathrm{a}}$, Ali Cam ${ }^{\mathrm{a}}$

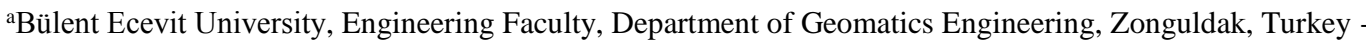 \\ (bakiogluoyaburcu@gmail.com, topan@beun.edu.tr, mustafa.ozendi@beun.edu.tr, alicam193@gmail.com)
}

KEY WORDS: Pan-sharpening, High Pass Filter, Spatial Metric, RASAT, GÖKTÜRK-2

\begin{abstract}
:
Pan-sharpened images of RASAT and GÖKTÜRK-2 satellites were generated using High Pass Filter (HPF) in this paper. GÖKTÜRK2 satellite has 11 bits radiometric resolution, $2.5 \mathrm{~m}$ GSD in panchromatic band and $5 \mathrm{~m}$ GSD in VNIR bands whereas RASAT has 8 bits radiometric resolution, $7.5 \mathrm{~m}$ GSD in panchromatic band and $15 \mathrm{~m}$ GSD in visible bands. Quantitative analysis was carried out by spatial metric while the while the products were qualitatively analysed with visual interpretation by an expert group. The values for spatial metric were estimated as 0.9678 and 0.9542 for RASAT and GÖKTÜRK-2, respectively. It can be concluded that the success of HPF is almost satisfactory considering the optimal value of spatial metric is 1 . The visual analysis shows the performance of GÖKTÜRK-2 is higher than RASAT since the higher radiometric and geometric resolution of GÖKTÜRK-2. All operations were run in SharpQ derived by the authors in Matlab environment.
\end{abstract}

\section{INTRODUCTION}

Thanks to the technological developments in remote sensing, various radiometric, geometric, spectral and temporal resolutions can be gained at the present time. Various types of image fusion technics are run for the images acquired from different type of sensors, for the purpose of increasing the potential of imageusage in different applications. One of these technics is pansharpening fusing the higher geometric resolution of panchromatic band and the higher spectral resolution of multispectral bands. By the way, a pan-sharpened image might reflect the best characteristics of geometric and spectral resolution of images. Many pan-sharpening methods and metrics for quantitative evaluation are available in the literature (Stathaki, 2011; Özendi et al., 2016). Each method has pros and cons characteristics since some of them highlights the geometric characteristics where some emphasis the spectral feature.

Pan-sharpening performance of RASAT images were subjected using various fusion methods and quantitative evaluation by statistical metrics (Özendi et al., 2016; Teke, 2016; Abdikan, 2016). GÖKTÜRK-2 images were also evaluated by Özendi et al. (2016). Özendi et al. (2016) were handled the kinds of pansharpening methods such as Principle Component Analysis (PCA), Intensity Hue Saturation (IHS), and Brovey. The image products were quantitatively evaluated by the statistical metrics such as Correlation Coefficient (CC), Root Mean Square Error (RMSE), Relative Average Spectral Error (RASE), Spectral Angle Mapper (SAM) and Erreur Relative Globale Adimensionnelle de Synthése (ERGAS). In addition to the previous studies, RASAT and GÖKTÜRK-2 images were evaluated by the HPF method and spatial metric. Both HPF and spatila metric stand out its geometric characteristics. The products were also visually analysed by an expert group.

\section{METHOD}

Among various type of pan-sharpening methods, HPS products the closest results to the original images with respect to the geometrical characteristics (Teke, 2016). The principle of HPF is to apply a filter to the panchromatic band, which is formed as follow:

$$
\text { filter }=\left[\begin{array}{ccc}
-1 & \cdots & -1 \\
\vdots & (2 r+1)^{2}-1 & \vdots \\
-1 & \cdots & -1
\end{array}\right]_{(2 r+1),(2 r+1)}
$$

The sum of this filter is 0 (zero). The $r$ value is the ratio of ground sampling distance (GSD) of multispectral and panchromatic bands $r=G S D_{M S} / G S D_{\text {Pan }}$. In our case, it set to 2 . Following the applying this filter to the panchromatic band, the new product can be calculated as:

$$
F_{i, j}=M S_{i, j}+\operatorname{Pan}_{i, j(w, h)}
$$

where, $F_{i, j}$ is pan-sharpened image, $M S_{i, j}$, is the multispectral bands, $P a n_{i, j}$, denotes the panchromatic band, and $P a n_{i, j(w, h)}$ means the filtered panchromatic band. $i, j$ is the row and column coordinates of filter with window size in $w$ (width) and $h$ (height) (Yusuf et al., 2013). The filtered band is convoluted by a weighting value suggested as 0.24 by Teke (2016).

For the statistical evaluation using spatial metric, both the original panchromatic and pan-sharpened image generated by HPF are re-filtered by the mask $[-1-1-1 ;-18-1 ;-1-$ $1-1]$ at first. Then the average $\mathrm{CC}$ derived by individual $\mathrm{CCs}$ between this new products (i.e. panchromatic and RGB bands of pan-sharpened image convoluted by the mask) is calculated (Palsson et al., 2012).

\section{APPLICATION}

\subsection{Image and test field}

RASAT and GÖKTÜRK-2 are the operational remote sensing satellites of Turkey. Their main characteristics are presented in Table 1. RASAT images can be downloaded from GEZGIN portal free-of-charge for Turkish citizens, whereas the GÖKTÜRK-2 images can be obtained free-of-charge for the noncommercial usage of governmental agencies and research/education institutions within Turkey. GÖKTÜRK-1 is

\footnotetext{
${ }^{*}$ Corresponding author.
} 
the newest satellite with $70 \mathrm{~cm}$ GSD in panchromatic band, and $2.8 \mathrm{~m}$ GSD in VNIR band.

\begin{tabular}{|l|l|l|}
\hline Launching date & 17 August 2011 & 18 December 2012 \\
\hline Altitude & $\sim 700 \mathrm{~km}$ & $\sim 700 \mathrm{~km}$ \\
\hline GSD & $\begin{array}{l}\text { Pan } 7.5 \mathrm{~m} \\
\text { RGB } 15 \mathrm{~m}\end{array}$ & $\begin{array}{l}\text { Pan } 2.5 \mathrm{~m} \\
\text { VNIR 5 m }\end{array}$ \\
\hline Swath Width & $30 \mathrm{~km}$ & $20 \mathrm{~km}$ \\
\hline $\begin{array}{l}\text { Radiometric } \\
\text { Resolution }\end{array}$ & $8 \mathrm{bit}$ & $11 \mathrm{bit}$ \\
\hline $\begin{array}{l}\text { Temporal } \\
\text { Resolution }\end{array}$ & 4 days & $2-3$ days \\
\hline Designer & $\begin{array}{l}\text { TUBITAK Space } \\
\text { Technologies } \\
\text { Research } \\
\text { Institute }\end{array}$ & $\begin{array}{l}\text { TUBITAK Space } \\
\text { Technologies } \\
\text { Research Institute, } \\
\text { Turkish Aerospace } \\
\text { Industries, Inc. }\end{array}$ \\
\hline Operator & $\begin{array}{l}\text { TUBITAK Space } \\
\text { Technologies } \\
\text { Research } \\
\text { Institute }\end{array}$ & Turkish Air Force \\
\hline
\end{tabular}

Table 1. Technical specifications of RASAT and GÖKTÜRK-2.

The images were acquired over Zonguldak city centre and its close surrounds. Zonguldak is a test site for evaluating the remotely sensed images since 2000s (Bayık, et al., 2016). The main characteristics of this test site is its roughness topography consisting of dense forest and urban areas and various kinds of land covers such as agricultural and industrial areas etc. Zonguldak is the major hard coal mining area of Turkey, which is still active in underground. Figure 1 shows the oblique view of the dominant topography and also the city centre.

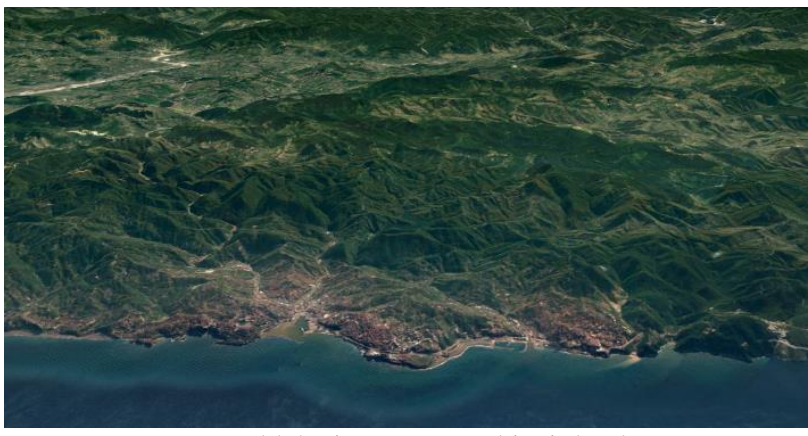

Zonguldak city centre and its inland

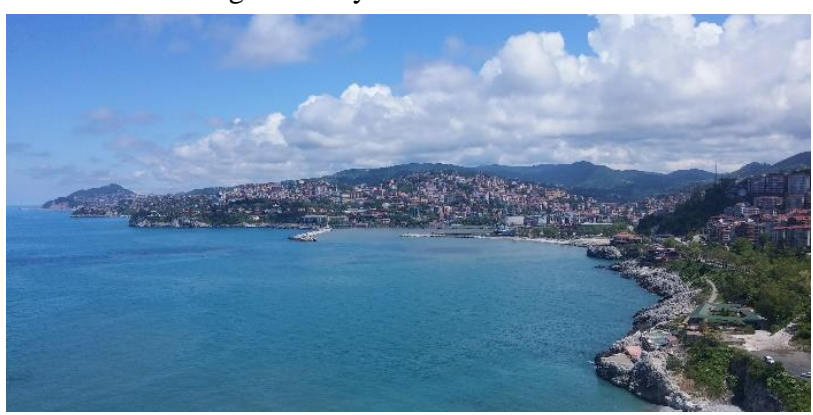

A scene from Zonguldak city centre

Figure 1. Zonguldak test site (Turkey).

The images in Level 1 format used in this research are shown in Figure 2. It is obvious that the GÖKTÜRK-2 has an effect of inter-detector responses. This radiometric effects were corrected by the radiometric calibration phase reported by Teke et al. (2016). Nevertheless, this radiometric distortion remained in the current images since GÖKTÜRK-2 images were dated 2014 in this study.

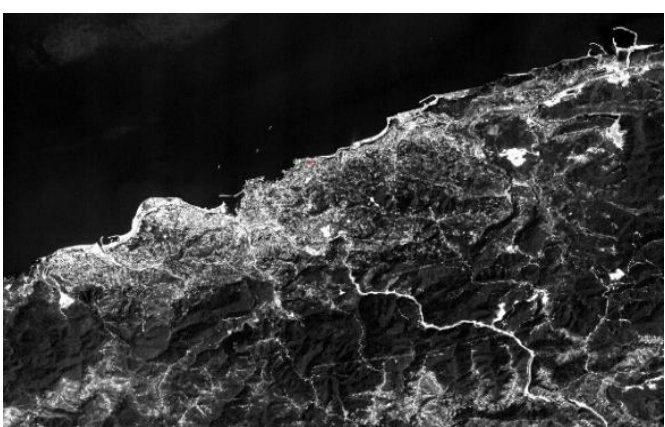

GÖKTÜRK-2 panchromatic

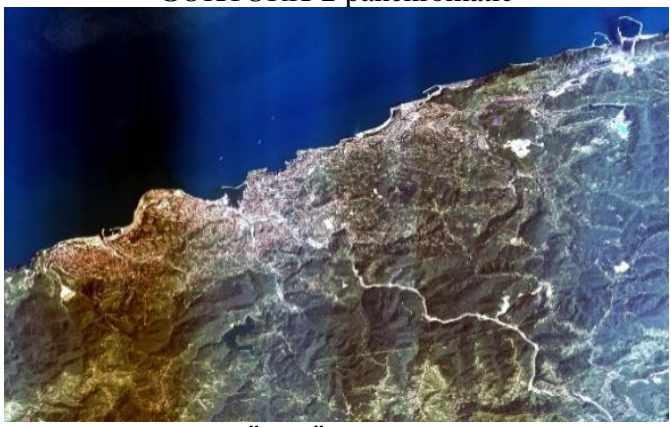

GÖKTÜRK-2 MS

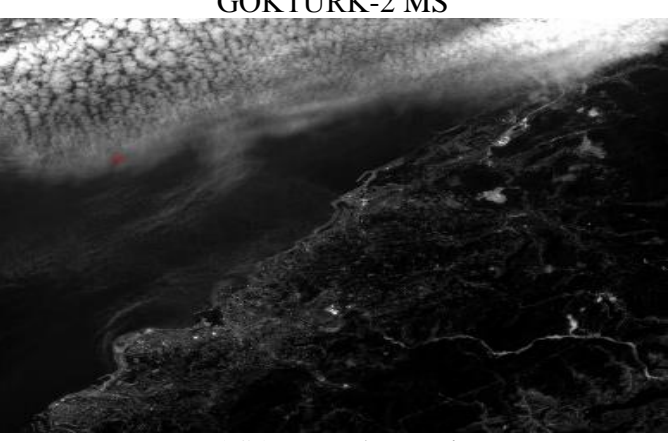

RASAT panchromatic

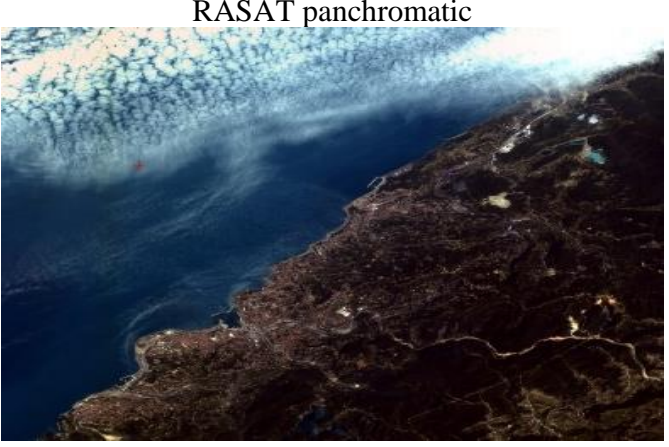

RASAT MS

Figure 2. GÖKTÜRK-2 and RASAT images in Level 1.

The pan-sharpening images were generated by SharpQ derived by the authors in Matlab environment. Figure 3 shows the pansharpened images generated. Results of GÖKTÜRK-2 reach more success since its sensor has more radiometric and geometric resolution than of RASAT. Correlation coefficients for RASAT image was 0.9678 and GÖKTÜRK-2 image was 0.9542, which both are close the optimal value (1) of this metric. This means the pan-sharpening of both images has a satisfactory success with respect to spatial metric.

Not only the quantitative analysis, but also a visual comparison was carried out for the qualitative analysis. 

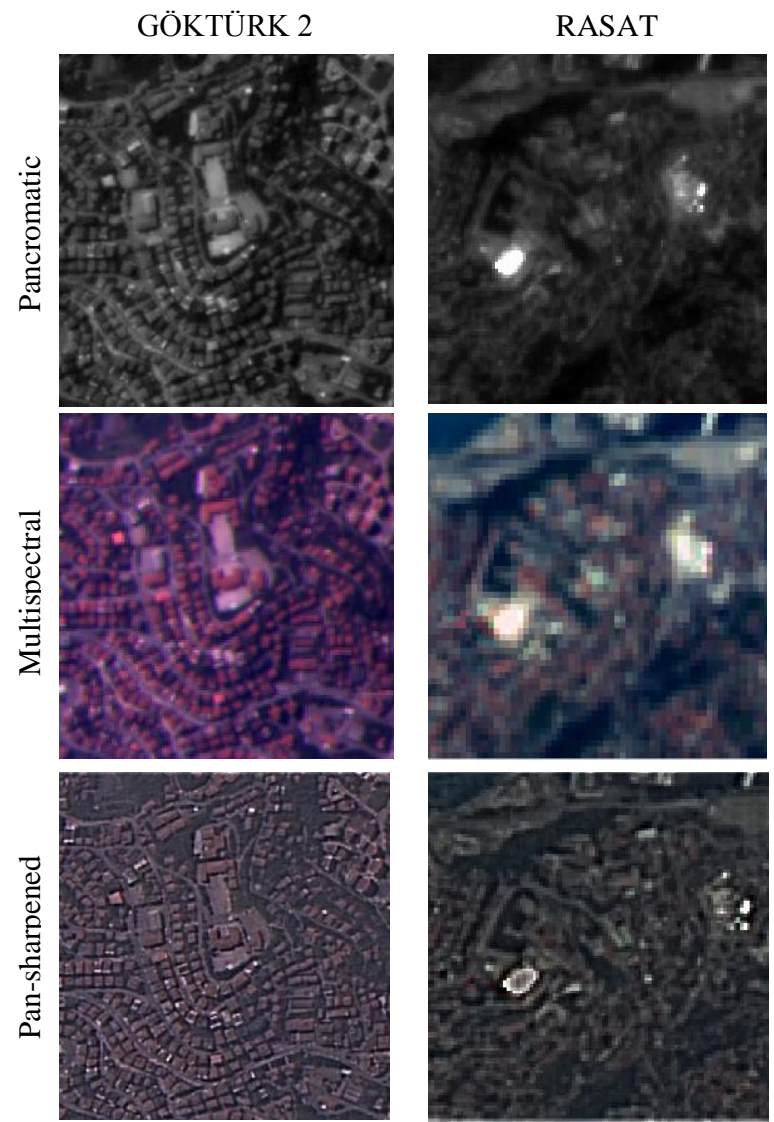

Figure 3. Pansharpened images of RASAT and GÖKTÜRK-2.

\subsection{VISUAL ANALYSIS}

Generally speaking, since GÖKTÜRK-2 has more geometric and radiometric resolution than RASAT, the visual quality of GÖKTÜRK-2 pan-sharpened images are higher than RASAT. The visual comparison was made for the urban and forest areas. As expected by the characteristics of HPF, this methods does not keep the colour, so its success on forest areas is poor than in urban areas.
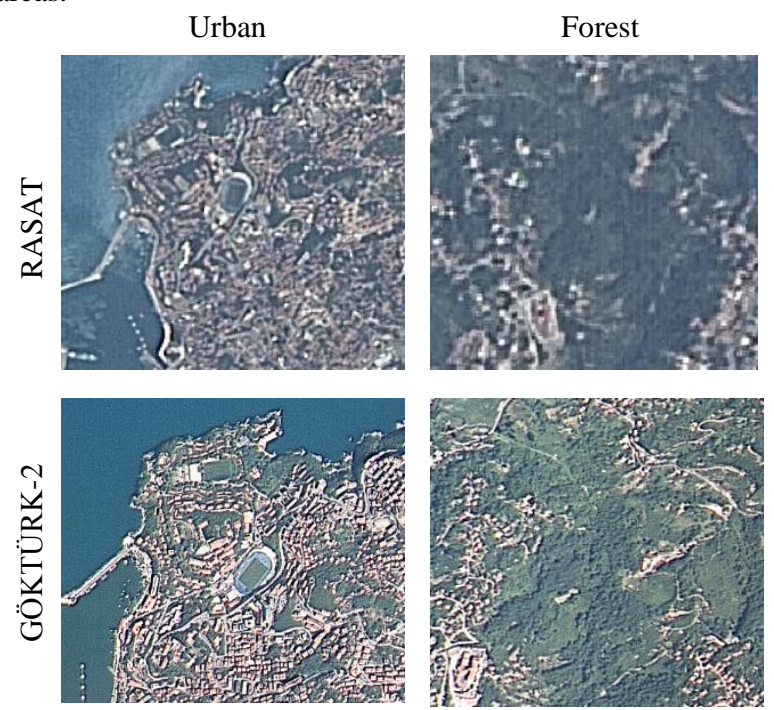

Figure 4. Viusal comparison in urban and forest areas.

\section{CONCLUSION}

In this study, the pan-sharpening performance of RASAT and GÖKTÜRK-2, two of three in-operation satellites of Turkey, were investigated. HPF is preferred for the pan-sharpening method, and the images were investigated using the spatial metric for quantitative analysis. The findings for correlation coefficients were 0.9678 for RASAT and 0.9542 for GÖKTÜRK-2, which both were close the optimal value (1) of this metric. Since HPF does not keep the colour information, the success of this method is relatively poor than in urban areas in the visual comparison.

\section{ACKNOWLEDGEMENTS}

The authors would like to thank Turkish Air Force for the support of GÖKTÜRK-2 images.

\section{REFERENCES}

Abdikan, S., 2017. RASAT verisi kullanarak farklı pankeskinleştirme yöntemlerinin istatistiksel analizi. Türk Coğrafya Dergisi 68, 57-62.

Bayık, Ç., Topan, H., Özendi, M., Oruç, M., Cam, A., Abdikan, S., 2016. Geospatial Analysis Using Remote Sensing Images: Case Studies of Zonguldak Test Field, International Archives of Photogrammetry Remote Sensing and Spatial Informaton Sciences. Copernicus Publications, Prague (Czech Republic), pp. 435-442.

Lu, D., Li, G., Moran, E., Dutra, L., Batistella, M., 2011. A comparison of multisensor integration methods for land cover classification in the Brazilian Amazon. GIScience \& Remote Sensing 48, 345-370.

Ozendi, M., Topan, H., Cam, A., Bayık, Ç., 2016a. Pan Sharpening Quality Investigation Of Turkish In-Operation Remote Sensing Satellites: Applications With Rasat And Göktürk-2 Images. International Archives of the Photogrammetry, Remote Sensing \& Spatial Information Sciences 42.

Ozendi, M., Topan, H., Oruc, M., Cam, A., 2016b. Pansharpening quality investigation of PLÉIADES-1A images. Geocarto International 31, 881-890.

Palsson, F., Sveinsson, J.R., Benediktsson, J.A., Aanaes, H., 2012. Classification of Pansharpened Urban Satellite Images. IEEE Journal of Selected Topics in Applied Earth Observations and Remote Sensing 5, 281-297.

Stathaki, T., 2011. Image fusion: algorithms and applications. Academic Press.

Teke, M., Seyfioglu, M.S., Agcal, A., Gurbuz, S.Z., 2014. Optimal pansharpening of RASAT satellite imagery, Signal Processing and Communications Applications Conference (SIU), 2014 22nd. IEEE, pp. 1967-1970.

Teke, M., Demirkesen, C., Haliloğlu, O., İmre, E., 2016. Göktürk-2 Uydusunun Bağıl ve Mutlak Çapraz Radyometrik Kalibrasyonu. Harita Dergisi, sayı 155: 32-52

Yusuf, Y., Sri Sumantyo, J.T., Kuze, H., 2013. Spectral information analysis of image fusion data for remote sensing applications. Geocarto International 28, 291-310. 